\title{
Endophthalmitis following pars plana vitrectomy: a literature review of incidence, causative organisms, and treatment outcomes
}

This article was published in the following Dove Press journal:

Clinical Ophthalmology

3I October 2014

Number of times this article has been viewed

\author{
Vivek Pravin Dave' \\ Avinash Pathengay ${ }^{2}$ \\ Stephen G Schwartz ${ }^{3}$ \\ Harry W Flynn Jr ${ }^{3}$ \\ 'Smt Kanuri Santhamma Center \\ for Vitreoretinal Diseases, ${ }^{2}$ Vitreo- \\ Retina and Uveitis Service, LV Prasad \\ Eye Institute, GMR Varalakshmi \\ Campus, Visakhapatnam, India; \\ ${ }^{3}$ Department of Ophthalmology, \\ Bascom Palmer Eye Institute, \\ University of Miami Miller School \\ of Medicine, Miami, FL, USA
}

\begin{abstract}
Endophthalmitis following pars plana vitrectomy is a very uncommon cause of endophthalmitis. Cases reported over the last decade show a decrease in incidence over time. To optimize visual outcome, early diagnosis and treatment are essential. In this review we report a summary of the incidence of endophthalmitis following vitrectomy, various risk factors for their occurrence, the microbiological profile and the visual outcomes post treatment.
\end{abstract}

Keywords: endophthalmitis, pars plana vitrectomy, visual outcome, prophylaxis, risk factors, sutureless vitrectomy

\section{Introduction}

Endophthalmitis is characterized by severe inflammation of the ocular tissues and fluids. Acute-onset postoperative infectious endophthalmitis is the most frequent category and may be associated with severe visual loss. The incidence of endophthalmitis varies with the surgical procedure performed. The most reported categories of endophthalmitis are following cataract surgery/intraocular lens implantation and following intravitreal injections. A review of the literature indicates the incidence in these scenarios to vary from $0.07 \%$ to $0.4 \%$ for cataract surgery and from $0.038 \%$ to $0.065 \%$ for intravitreal injections. ${ }^{1-5}$ Endophthalmitis following pars plana vitrectomy (PPV) is an uncommon cause of endophthalmitis (Figure 1). The reported rates of post-PPV endophthalmitis have been decreasing over the last decade. In this review, the incidence of post-PPV endophthalmitis, risk factors for occurrence, microbiological profile, and treatment outcomes in the sutureless PPV era are reported.

\section{Incidence}

Endophthalmitis following PPV is relatively uncommon. Over the years, there have been various studies which reported incidences of endophthalmitis after PPV (Table 1). ${ }^{6-13}$ The incidence ranges between $0.03 \%$ and $0.14 \%$ for $20 \mathrm{G}$ PPV. None of the cases had additional concurrent surgery.

\section{Incidence in transconjunctival sutureless vitrectomy}

The first reported case of endophthalmitis in transconjunctival sutureless vitrectomy (TSV) surgery was in 2005 following a 25 G PPV (Table 2)..$^{14}$ The vitreous sample was negative on Gram stain and culture. After intravitreal and oral antibiotics, vision increased from hand motion close to face to $6 / 6$ at the 3-week follow-up visit.
Vitreo-Retina and Uveitis Service, LV Prasad Eye Institute, GMR Varalakshmi Campus, Visakhapatnam, India

Tel +91 9989156789

Email avinash@lvpei.org 


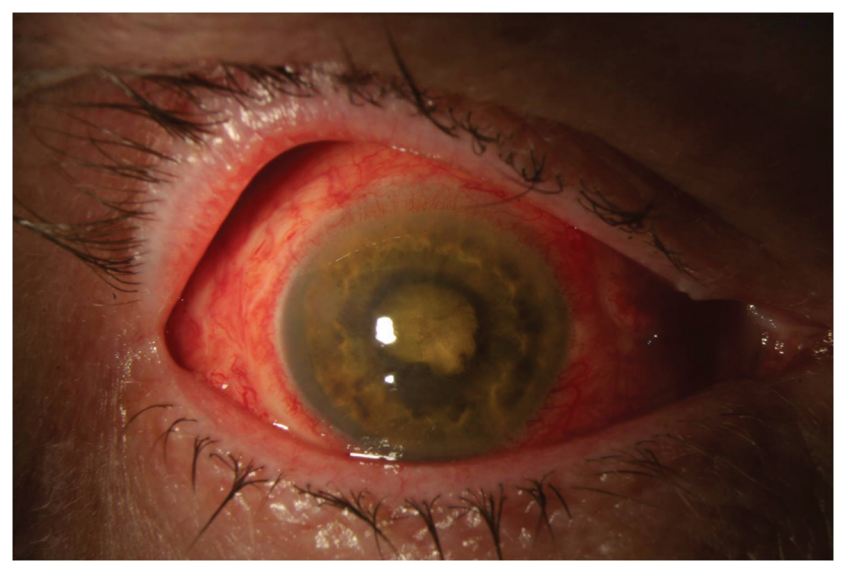

Figure I Anterior segment photograph of a patient with endophthalmitis following pars plana vitrectomy operated for rhegmatogenous retinal detachment. Cultures were positive for Bacillus cereus. Visual acuity was light perception after treatment.

Older studies comparing $25 \mathrm{G}$ with $20 \mathrm{G}$ PPV generally reported higher rates in the $25 \mathrm{G}$ group. Kunimoto and Kaiser compared endophthalmitis rates after $20 \mathrm{G}$ and $25 \mathrm{G} \mathrm{PPV}$ in 2007 and reported $0.23 \%$ in $25 \mathrm{G}$ cases as compared with $0.018 \%$ in $20 \mathrm{G}$ cases, which was statistically significant. ${ }^{15}$ Both the groups had final median visual acuity of counting fingers. Shaikh et al reviewed 129 consecutive cases of $20 \mathrm{G}$ and 129 consecutive cases of 25G PPV in 2007 and reported two cases $(1.55 \%)$ of endophthalmitis in the $25 \mathrm{G}$ group and none in the $20 \mathrm{G}$ group. ${ }^{16}$ Chen et al in 2009 reported a nonsignificantly higher rate of endophthalmitis in $25 \mathrm{G}(0.23 \%)$ compared with $20 \mathrm{G}(0.03 \%) \mathrm{PPV} .{ }^{17} \mathrm{Scott}$ et al in a multicenter study 2008 reported a significantly higher rate of endophthalmitis in $25 \mathrm{G} \mathrm{TSV}(0.84 \%)$ versus 20 G PPV (0.03\%). ${ }^{18}$ Of these, most cases (9/11) in the TSV group that developed endophthalmitis had straight incisions which may have been a possible risk factor.

However, other studies, and especially newer studies, have reported no significant difference in endophthalmitis

Table I Incidence of endophthalmitis following pars plana vitrectomy in $20 \mathrm{G}$ surgery

\begin{tabular}{|c|c|c|c|}
\hline Reference & Year & Case occurrence & Incidence \\
\hline Ho and Tolentino ${ }^{6}$ & 1984 & $4 / 2,817$ & $0.14 \%$ \\
\hline Cohen et $\mathrm{al}^{8}$ & 1995 & $18 / 12,216$ & $0.15 \%$ \\
\hline Aaberg et $\mathrm{al}^{7}$ & 1998 & $3 / 6,557$ & $0.04 \%$ \\
\hline Zhang et al $^{9}$ & 2003 & $3 / 7,000$ & $0.04 \%$ \\
\hline Eifrig et al ${ }^{10}$ & 2004 & $6 / 15,326$ & $0.03 \%$ \\
\hline Sakamoto et $\mathrm{al}^{45}$ & 2004 & I/I,886 & $0.05 \%$ \\
\hline Joondeph et al"I & 2005 & $5 / 10,397$ & $0.04 \%$ \\
\hline Mollan et $\mathrm{al}^{12}$ & 2009 & $2 / 5,278$ & $0.03 \%$ \\
\hline Chen et $\mathrm{al}^{17}$ & 2009 & $\mathrm{I} / 3,046$ & $0.03 \%$ \\
\hline Scott et $\mathrm{al}^{21}$ & 2011 & $\mathrm{I} / 4,403$ & $0.02 \%$ \\
\hline
\end{tabular}

Table 2 Incidence of endophthalmitis in transconjunctival sutureless vitrectomy

\begin{tabular}{|c|c|c|c|}
\hline Reference & Year & Case occurrence & Incidence \\
\hline Shaikh et al ${ }^{16}$ & 2007 & $2 / 129$ & $1.55 \%$ \\
\hline Kunimoto and Kaiser ${ }^{15}$ & 2007 & $\mathrm{I} / 443$ & $0.22 \%$ \\
\hline Scott et $\mathrm{al}^{18}$ & 2008 & $1 / 119$ & $0.84 \%$ \\
\hline Shimada et al ${ }^{19}$ & 2008 & $1 / 3,343$ & $0.03 \%$ \\
\hline Chen et a $\left.\right|^{17}$ & 2009 & $|/ 43|$ & $0.23 \%$ \\
\hline Hu et $\mathrm{al}^{20}$ & 2009 & $\mathrm{I} / \mathrm{I}, 424$ & $0.07 \%$ \\
\hline Scott et $\mathrm{a}^{21}$ & 2011 & $2 / 4,|5|$ & $0.04 \%$ \\
\hline Mutoh et $\mathrm{al}^{46}$ & 2012 & $4 / 502$ & $0.79 \%$ \\
\hline
\end{tabular}

rates between the two groups, perhaps reflecting advances in wound construction and improvements in surgical technique. ${ }^{19-21}$ There are also reports which show very rare occurrence of endophthalmitis post TSV. ${ }^{22,23}$

In a 2-year, prospective, nationwide surveillance study from the UK, the rate of endophthalmitis after PPV was 28 per $48,433(0.058 \%)$. There were no statistically significant differences in the rates between small gauge TSV and $20 \mathrm{G}$ PPV. ${ }^{24}$ Culture positivity was reported in $60.7 \%$ of cases. Outcomes were generally poor, with $29.6 \%$ of eyes having final visual outcomes of light perception, no light perception, or evisceration. ${ }^{25}$

\section{Predisposing factors}

There are certain factors that may increase the incidence of post-PPV endophthalmitis (Table 3). These include inadequate wound closure, postoperative hypotony, vitreous incarceration at a sclerotomy site, aqueous intraocular tamponade, additional concomitant intraocular procedures, and surgeon learning curve.

\section{Inadequate wound closure and hypotony}

In the first reported case of endophthalmitis following TSV, the authors speculated lack of adequate wound closure and wound leak to be possible contributory factors. ${ }^{14}$ The hypotony from a sclerotomy leak may allow ingress of microorganisms into the vitreous cavity from the ocular surface. ${ }^{26-28} \mathrm{An}$ optical coherence tomography study reported the benefits of a sutured sclerotomy over an unsutured one with respect to wound closure. ${ }^{29}$ Other studies have reported ingress of India ink across unsutured sclerotomies while no ink was shown to enter the globe in cases of sutured sclerotomies. ${ }^{30-34}$

\section{Sclerotomy site vitreous incarceration (vitreous wick)}

Another potential risk factor for endophthalmitis may be vitreous incarceration at a sclerotomy site. Endoscopic 
Table 3 Risk factors associated with endophthalmitis after pars plana vitrectomy

\begin{tabular}{ll}
\hline Surgery-related risk factors & Patient-related risk factors \\
\hline Inadequate wound closure & Diabetes mellitus or other causes of immune compromise \\
Hypotony & Trauma or excessive eye rubbing \\
Vitreous incarceration & Noncompliance with treatment \\
Endotamponade agent (air, gas, or silicone oil) & \\
Subconjunctival and intravitreal injections & \\
Surgeon learning curve (non-beveled sclerotomies) & \\
\hline
\end{tabular}

evaluation of autopsied vitrectomized eyes have reported vitreous incarceration at the port sites. ${ }^{34,35}$ In an unsutured wound, this can allow communication of ocular surface bacteria to the inside of the globe by a "vitreous wick" phenomenon wherein microorganisms can migrate from the exterior into the vitreous cavity along a strand of vitreous prolapsing out of the unsutured sclerotomy wound. ${ }^{36}$

\section{Type of intraocular tamponade}

In earlier reports, ${ }^{15,18}$ no intraocular gas or oil tamponade following PPV was used. It was hypothesized that balanced salt solution is likely to provide poorer wound integrity at the sclerotomy site compared with tamponade agents due to different surface tension properties. Higher surface tension properties of air, gas, and silicone oil may prevent fluid from egressing across the sclerotomy. ${ }^{37}$ It is also suspected that air, gas, and silicone oil do not support bacterial growth as well as balanced salt solution.

\section{Contamination of the vitreous cavity}

Vitreous contamination rates by microorganisms are reported to be significantly higher during TSV than during $20 \mathrm{G}$ surgery (22\% versus $2.4 \%) .{ }^{38,39}$ Although the penetrating instruments in their study were not cultured, the most common organism isolated in their study was Propionibacterium acnes which is consistent with residual ocular surface flora. The lower incidences of bacterial contamination during $20 \mathrm{G}$ surgery may be associated with less risk of surgical instruments directly contacting the conjunctiva.

\section{Associated pharmacotherapy}

Subconjunctival antibiotics are sometimes used at the conclusion of intraocular procedures. With emergence of TSV, many centers have done away with this practice. In addition, some surgeons use intravitreal triamcinolone, dexamethasone, or bevacizumab injections at the end of surgery. These additional injections, along with the practice of eliminating subconjunctival antibiotics, could potentially increase the risk of endophthalmitis. ${ }^{18}$

\section{Surgeon learning curve}

As in any other ophthalmic surgery, vitrectomy also has a learning curve. In one study, surgeons beginning to transition from $20 \mathrm{G}$ to TSV surgeries were reported to face higher rates of hypotony and wound leakage, which are potential risk factors for endophthalmitis. ${ }^{27}$ A common challenge during the learning curve is a poorly constructed incision, which may lead to postoperative wound leakage.

\section{Diabetes mellitus}

There is a theoretical association between diabetes mellitus and an increased risk of endophthalmitis following PPV. As diabetics are relatively immunologically compromised, there is a potential for an increased rate of procedure-related infections. Diabetics are relatively more likely to have longer surgeries for proliferative diabetic retinopathy and associated complications such as traction retinal detachment. These surgeries may have multiple insertions and removal of instruments and may be combined with cataract surgery, increasing the risk of endophthalmitis. In most studies describing endophthalmitis, a substantial proportion of the patients were diabetic. ${ }^{6,8,10-12,15,17-19,40}$

\section{Microbiological spectrum}

Multiple studies have implicated a variety of microorganisms. The reported bacteria include coagulase-negative staphylococci, Pseudomonas species, Propionibacterium, enterococci, and Bacillus species. Most studies report that coagulase-negative staphylococci is the most common organism. ${ }^{40-44}$

\section{Clinical features}

Clinical features of endophthalmitis following PPV are similar to those of endophthalmitis following cataract surgery. Typically patients present acutely with a hypopyon and dense vitritis. Some cases, however, may demonstrate a delayed presentation, perhaps due to the lack of vitreous and consequent lack of severe posterior segment inflammation until later in the course of the disease. Possibly because of coexisting advanced 
vitreoretinal diseases, the visual outcomes after treatment of endophthalmitis following PPV are often poor.

\section{Prophylaxis}

As in any case of endophthalmitis, early detection and prompt treatment are important elements in having a successful clinical outcome. The following preoperative, intraoperative, and postoperative measures can be taken to theoretically reduce the incidence of post-PPV endophthalmitis. ${ }^{34}$

\section{Preoperative preparation}

Preoperative preparation of lids and lashes with povidoneiodine $10 \%$ solution is highly recommended as it has been shown to reduce ocular flora in these areas. In patients with reported iodine allergy, chlorhexidine gluconate can be considered for the eye lids. ${ }^{25}$ However, povidone-iodine 5\% should be used directly on the ocular surface.

Usage of lid speculum and adhesive surgical drape should ensure that no eye lashes are exposed in the surgical field. If a few lashes stay exposed after draping, consider redraping or removing the exposed lashes. In patients with active ipsilateral eye lid infection (stye or severe blepharitis), elective vitreous surgery can be postponed until the inflammation is treated.

\section{Intraoperative care}

Some centers use antibiotics in the infusion fluid, but this is a controversial practice. At this time, there have been no reported studies comparing the incidence of post-PPV endophthalmitis in eyes with or without antibiotics in the infusion fluid.

During small-gauge TSV, it is recommended to displace the conjunctiva before making a trocar entry. After entry, the conjunctiva can be released to its original position. This ensures that the conjunctival entry and the scleral entry wound are not in the same line, which may reduce risks of bacterial entry into the vitreous cavity.
During small-gauge TSV, scleral incisions should be beveled and not perpendicular to the scleral surface. A beveled incision offers better wound closure, reducing risks of sclerotomy leak.

After small-gauge TSV cannula removal, it is important to check for wound leak or vitreous wicking. If the eye goes soft or there is egress of air bubbles, the sclerotomy should be sutured. One may consider suturing the conjunctiva and the sclerotomy separately in such cases.

\section{Postoperative care}

Complaints of pain and blurred vision should alert the surgeon to look for subtle signs of endophthalmitis. The Endophthalmitis Vitrectomy Study did not enroll patients with post-PPV endophthalmitis, so its results do not directly apply to these cases. Nevertheless, certain principles apply. Vitreous tap and inject is quick, inexpensive, and does not require access to an operating room or specialized vitrectomy equipment. Prior to antibiotic injection, a vitreous cavity sample should be obtained for culture and sensitivity. If the vitreous cavity is filled with gas or silicone oil, a sample from the anterior chamber can be taken. A negative microbiology report does not rule out endophthalmitis. In case of doubt, one can repeat the sampling and treat with a broad-spectrum intravitreal antibiotic combination.

\section{Culture positivity}

Various studies have demonstrated culture positivity rates in cases of post-PPV endophthalmitis (Table 4). Culture positivity is very varied across studies. On average, about $70 \%$ of all samples across studies have shown a positive microbiology culture report. In a large multicenter study, Cohen et $\mathrm{al}^{8}$ had 16 culture-positive cases out of 18 cases (89\%) of endophthalmitis post vitrectomy. Abi-Ayad et al have shown the lowest incidence of $29 \%$ (4/14 cases).

Table 4 Culture positivity rates in endophthalmitis after pars plana vitrectomy

\begin{tabular}{|c|c|c|c|c|}
\hline Reference & Year & Culture positivity rate & Culture-positive cases (n) & Predominant organism \\
\hline Cohen et $\mathrm{al}^{8}$ & 1995 & $89 \%$ & $16 / 18$ & CNS \\
\hline Aaberg et $\mathrm{al}^{7}$ & 1998 & $100 \%$ & $3 / 3$ & CNS \\
\hline Eifrig et al ${ }^{10}$ & 2004 & $83 \%$ & $5 / 6$ & Staphylococcus aureus \\
\hline Joondeph et al" & 2005 & $100 \%$ & $5 / 5$ & CNS \\
\hline Abi-Ayad et $\mathrm{al}^{40}$ & 2007 & $29 \%$ & $4 / 14$ & CNS \\
\hline Scott et $\mathrm{al}^{18}$ & 2008 & $100 \%$ & $1 / 1$ & CNS \\
\hline Shimada et al ${ }^{19}$ & 2008 & $100 \%$ & $2 / 2$ & MRSA, Enterococcus faecalis \\
\hline Chen et $\mathrm{al}^{17}$ & 2009 & $50 \%$ & $1 / 2$ & Staphylococcus aureus \\
\hline Mollan et al ${ }^{12}$ & 2009 & $0 \%$ & - & None \\
\hline Scott et $\mathrm{a}^{21}$ & 2011 & $50 \%$ & $2 / 3$ & CNS \\
\hline Mutoh et $\mathrm{a}^{46}$ & 2012 & $0 \%$ & - & None \\
\hline
\end{tabular}

Abbreviations: CNS, coagulase-negative staphylococci; MRSA, methicillin-resistant Staphylococcus aureus. 
Table 5 Visual acuity outcomes in reported series of post-pars plana vitrectomy endophthalmitis after treatment

\begin{tabular}{|c|c|c|c|c|}
\hline Reference & Diagnosis at time of PPV & Year & Cases (n) & Visual outcome at last visit \\
\hline Cohen et al ${ }^{8}$ & ERM, MH, PDR & 1995 & $18 / 12,216$ & $\begin{array}{l}3 \mathrm{EV}, 6 \mathrm{NLP}, \mathrm{I} \mathrm{HM}, \mathrm{I} \mathrm{LP}, 2 \\
20 / 400, \text { I 20/50, I 20/30, I 20/25 } \\
\text { and } 220 / 20\end{array}$ \\
\hline Aaberg et $\mathrm{al}^{7}$ & - & 1998 & $3 / 6,557$ & All eyes NLP \\
\hline Eifrig et al ${ }^{10}$ & $\begin{array}{l}\text { PDR, macular pucker, } \\
\text { recurrent RD }\end{array}$ & 2004 & $6 / 15,326$ & $\begin{array}{l}3 \text { NLP, I LP, I 2/200 and I } \\
20 / 200\end{array}$ \\
\hline Joondeph et al" & VH, MH, ERM, RD & 2005 & $5 / 10,397$ & $\begin{array}{l}2 \text { NLP, I HM, I 20/200 and I } \\
20 / 50\end{array}$ \\
\hline Shaikh et al ${ }^{16}$ & ERM & 2007 & $2 / 129$ & One $20 / 400$, one $20 / 40$ \\
\hline Scott et al ${ }^{18}$ & ERM, PDR, CRVO, disc pit & 2008 & $13 / 7,682$ & $\begin{array}{l}\text { I LP, I HM, I 20/400, I 5/200, } \\
2 \text { 20/I50, I 20/100, } 2 \text { 20/20, } 2 \\
20 / 40,220 / 30\end{array}$ \\
\hline Shimada et al ${ }^{19}$ & ERM & 2008 & $2 / 6,935$ & Both cases NLP \\
\hline Chen et $\mathrm{al}^{17}$ & VH, TRD with VH & 2009 & $2 / 3,477$ & One $20 / 200$, one $20 / 125$ \\
\hline Mollan et al ${ }^{12}$ & $\mathrm{MH}, \mathrm{PDR}$ & 2009 & $2 / 5,278$ & One $1 / 60$, one $6 / 12$ \\
\hline Scott et $\mathrm{a}^{21}$ & $\mathrm{RD}, \mathrm{MH}, \mathrm{ERM}$ & 2011 & $3 / 8,554$ & One $\mathrm{HM}$, one $20 / 100$, one $20 / 40$ \\
\hline Mutoh et $\mathrm{a}^{46}$ & CME, ERM & 2012 & $4 / 502$ & $\begin{array}{l}\text { One } 20 / 30 \text {, one } 20 / 100 \text {, one } \\
20 / 20 \text {, one } 20 / 25\end{array}$ \\
\hline
\end{tabular}

Abbreviations: PPV, pars plana vitrectomy; NLP, no light perception; LP, light perception; HM, hand motion vision; ERM, epiretinal membrane; RD, retinal detachment; $\mathrm{VH}$, vitreous hemorrhage; CRVO, central retinal vein occlusion; PDR, proliferative diabetic retinopathy; CME, cystoid macular edema; MH, macular hole; TRD, traction retinal detachment; EV, eviscerated.

\section{Visual outcomes}

Visual outcomes after treatment of post-PPV endophthalmitis are varied in the literature. In general, the outcomes are worse than that after cataract surgery, perhaps due to the underlying retinal pathology and associated poor visual potential. Although good visual outcomes have been reported in a few patients, most large studies show poor post-treatment visual gain (Table 5).

\section{Conclusion}

Endophthalmitis after PPV is a rare but potentially very serious event. The outcomes are often poor despite prompt and appropriate treatment. The risk was potentially higher in the initial years of TSV surgeries, which could be hypothesized to be due to leaking sclerotomies. However, most recent studies have reported very low rates.

\section{Disclosure}

SGS has been a consultant for Bausch \& Lomb and Santen, and has received lecture fees from ThromboGenics. The other authors have no conflicts of interest to report in this work.

\section{References}

1. Ferro JF, de Pablos M, Logrono MJ, et al. Postoperative contamination after using vancomycin and gentamicin during phacoemulsification. Arch Ophthalmol. 1997;115:165-170.

2. Aaberg TM Jr, Flynn HW Jr, Murray TG. Intraocular ceftazidime as an alternative to the aminoglycosides in the treatment of endophthalmitis. Arch Ophthalmol. 1994;12:18-19.
3. Kattan HM, Flynn HW Jr, Pflugfelder SC, et al. Nosocomial endophthalmitis survey: current incidence of infection after intraocular surgery. Ophthalmology. 1991;98:227-238.

4. Hughes DS, Hill RJ. Infectious endophthalmitis after cataract surgery. Br J Ophthalmol. 1994;78:227-232.

5. McCannel CA. Meta-analysis of endophthalmitis after intravitreal injection of anti-vascular endothelial growth factor agents. Causative organisms and possible treatment strategies. Retina. 2011;31: 654-661.

6. Ho PC, Tolentino FI. Bacterial endophthalmitis after closed vitrectomy. Arch Ophthalmol. 1984;102:207-210.

7. Aaberg TM, Flynn HW Jr, Schiffman J, Newton J. Nosocomial acute-onset postoperative endophthalmitis survey. A 10-yr review of incidences and outcomes. Ophthalmology. 1998;105:1004-1010.

8. Cohen SM, Flynn HW Jr, Murray TG, Smiddy WE. Endophthalmitis after pars plana vitrectomy. The post vitrectomy endophthalmitis study group. Ophthalmology. 1995;102:702-712.

9. Zhang S, Ding X, Hu J, Gao R. [Clinical features of endophthalmitis after vitreoretinal surgery]. Yan Ke Хие Вao. 2003;19:39-43. Chinese.

10. Eifrig CW, Scott IU, Flynn HW Jr, Smiddy WE, Newton J. Endophthalmitis after pars plana vitrectomy: incidence, causative organisms, and visual acuity outcomes. Am J Ophthalmol. 2004;138:799-802.

11. Joondeph BC, Blanc JP, Polkinghorne PJ. Endophthalmitis after pars plana vitrectomy: a New Zealand experience. Retina. 2005;25: 587-589.

12. Mollan SP, Mollan AJ, Konstantinos C, Durrani OM, Butler L. Incidence of endophthalmitis following vitreoretinal surgery. Int Ophthalmol. 2009;29:203-205.

13. Wykoff CC, Parrott MB, Flynn HW Jr, et al. Nosocomial acuteonset postoperative endophthalmitis at a university teaching hospital. 2010;150:392-398.

14. Taylor SR, Aylward GW. Endophthalmitis following 25-gauge vitrectomy. Eye. 2005;19:1228-1229.

15. Kunimoto DY, Kaiser RS; Wills Retina Service. Incidence of endophthalmitis after 20 and 25 gauge vitrectomy. Ophthalmology. 2007; 114:2133-2137.

16. Shaikh S, Ho S, Richmond PP, Olson JC, Barnes CD. Untoward outcomes in 25-gauge versus 20-gauge vitreoretinal surgery. Retina. 2007;27:1048-1053. 
17. Chen JK, Khurana RN, Nguyen QD, Do DV. The incidence of endophthalmitis following transconjunctival sutureless 25 vs 20 gauge vitrectomy. Eye. 2009;23:780-784.

18. Scott IU, Flynn HW Jr, Dev S, et al. Endophthalmitis after 25 gauge and 20 gauge pars plana vitrectomy: incidence and outcomes. Retina. 2008;28:138-142.

19. Shimada H, Nakashizuka H, Hattori T, Mori R, Mizutani Y, Yuzawa M. Incidence of endophthalmitis after 20 and 25 gauge vitrectomy: causes and prevention. Ophthalmology. 2008;115:2215-2220.

20. Hu AYH, Bourges JL, Shah SP, et al. Endophthalmitis after pars plana vitrectomy. Ophthalmology. 2009;116:1360-1365.

21. Scott IU, Flynn HW Jr, Acar N, et al. Incidence of endophthalmitis after 20 -gauge vs 23-gauge vs 25-gauge pars plana vitrectomy. Graefes Arch Clin Exp Ophthalmol. 2011;249:377-380.

22. Parolini B, Romanelli F, Prigione G, Pertile G. Incidence of endophthalmitis in a large series of 23-gauge and 20-gauge transconjunctival pars plana vitrectomy. Graefes Arch Clin Exp Ophthalmol. 2009;247:895-898.

23. Haas A, Seidel G, Steinbrugger I, et al. Twenty-three-gauge and 20-gauge vitrectomy in epiretinal membrane surgery. Retina. 2010;30: $112-116$.

24. Park JC, Ramasamy B, Shaw S, Prasad S, Ling RH. A prospective and nationwide study investigating endophthalmitis following pars plana vitrectomy: incidence and risk factors. $\mathrm{Br} J$ Ophthalmol. 2014;94:529-533.

25. Wykoff CC, Flynn HW Jr, Han DP. Allergy to povidone-iodine and cephalosporins: the clinical dilemma in ophthalmic usage. Am J Ophthalmol. 2011;151:4-6.

26. Aylward GW. Sutureless vitrectomy. Ophthalmologica. 2011;225: 67-75.

27. Fujii GY, De Juan E, Humayun MS, et al. Initial experience using the transconjunctival sutureless vitrectomy system for vitreoretinal surgery. Ophthalmology. 2002;109:1814-1820.

28. Acar N, Kapran Z, Unver Y, Altan T, Ozdogan S. Early postoperative hypotony after 25-gauge sutureless vitrectomy with straight incisions. Retina. 2008;28:545-552.

29. Chen D, Lian Y, Cui L, Lu F, Ke Z, Song Z. Sutureless vitrectomy incision architecture in the immediate post-operative period evaluated in vivo using optical coherence tomography. Ophthalmology. 2010;117:2003-2009.

30. Gupta OP, Maguire JI, Eagle RC Jr, et al. The competency of pars plana vitrectomy incisions: a comparative histologic and spectrophotometric analysis. Am J Ophthalmol. 2009;147:243-250.

31. Singh RP, Bando H, Brasil OF, et al. Evaluation of wound closure using different incision techniques with 23-gauge and 25-gauge microincision vitrectomy systems. Retina. 2008;28:242-248.

32. Thompson JT. Advantages and limitations of small gauge vitrectomy. Surv Ophthalmol. 2011;56:162-172.
33. Meredith TA. Antimicrobial pharmacokinetics in endophthalmitis treatment: studies of ceftazidime. Trans Am Ophthalmol. 1993;91: 653-699.

34. Kaiser RS, Prenner J, Scott IU, et al. The Microsurgical Safety Task Force: evolving guidelines for minimizing the risk of endophthalmitis associated with microincisional vitrectomy surgery. Retina. 2010;30:692-699.

35. Nagpal M, Wartikar S, Nagpal K. Comparisons of clinical outcomes and wound dynamics of sclerotomy ports of 20, 23, and 25 gauge vitrectomy. Retina. 2009;29:225-231.

36. Chen SD, Mohammed Q, Bowling B, Patel CK. Vitreous wick syndrome - a potential cause of endophthalmitis after intravitreal injection of triamcinolone through the pars plana. Am J Ophthalmol. 2004;137:1159-1160

37. Chiang A, Kaiser R, Avery R, et al. Endophthalmitis in microincision vitrectomy. Outcomes of gas-filled eyes. Retina. 2011;31:1513-1517.

38. Tominaga A, Oshima Y, Wakabayashi T, Sakaguchi H, Hori Y, Maeda N. Bacterial contamination of the vitreous cavity associated with transconjunctival 25-gauge microincision vitrectomy surgery. Ophthalmology. 2010;117:811-817.

39. Fujii GY, Juan E Jr, Humayun MS, et al. A new 25-gauge instrument system for transconjunctival sutureless vitrectomy surgery. Ophthalmology. 2002;109:1807-1812.

40. Abi-Ayad N, Gambrelle J, Duquesne N, Fleury J, Grange JD, Kodjikian L. [Endophthalmitis after plana vitrectomy: incidence, microbiology and visual outcomes]. J Fr Ophthalmol. 2007;30: 397-402. French.

41. Wu L, Berrocal MH, Arévalo JF, Carpentier C, et al. Endophthalmitis after pars plana vitrectomy: results of the Pan American Collaborative Retina Study Group. Retina. 2011;31:673-678.

42. Oshima Y, Kadonosono K, Yamaji H, et al. Multicenter survey with a systematic overview of acute-onset endophthalmitis after transconjunctival microincision vitrectomy surgery. Japan Microincision Vitrectomy Surgery Study Group. Am J Ophthalmol. 2010;150:716-725.e1.

43. Wani VB, Al Sabti K, Kumar N, et al. Endophthalmitis after vitrectomy and vitrectomy combined with phacoemulsification: incidence and visual outcomes. Eur J Ophthalmol. 2009;19:1044-1049.

44. Taban M, Ufret-Vincenty RL, Sears JE. Endophthalmitis after 25-gauge transconjunctival sutureless vitrectomy. Retina. 2006;26:830-831.

45. Sakamoto T, Enaida H, Kubota T, et al. Incidence of acute endophthalmitis after triamcinolone-assisted pars plana vitrectomy. Am J Ophthalmol. 2004;138:137-138.

46. Mutoh T, Kadoya K, Chikuda M. Four cases of endophthalmitis after 25-gauge pars plana vitrectomy. Clin Ophthalmol. 2012;6: 1393-1397.
Clinical Ophthalmology

\section{Publish your work in this journal}

Clinical Ophthalmology is an international, peer-reviewed journal covering all subspecialties within ophthalmology. Key topics include: Optometry; Visual science; Pharmacology and drug therapy in eye diseases; Basic Sciences; Primary and Secondary eye care; Patient Safety and Quality of Care Improvements. This journal is indexed on Submit your manuscript here: http://www.dovepress.com/clinical-ophthalmology-journal
Dovepress

PubMed Central and CAS, and is the official journal of The Society of Clinical Ophthalmology (SCO). The manuscript management system is completely online and includes a very quick and fair peer-review system, which is all easy to use. Visit http://www.dovepress.com/ testimonials.php to read real quotes from published authors. 